\title{
Prescription Pattern Analysis of Antidiabetic Drugs in Diabetes Mellitus and Associated Comorbidities
}

\begin{abstract}
Background:The treatment options for Diabetes mellitus and their prescribing has increased over years. This needs appropriate selection of drugs. The main objective of this study was to highlight the current prescribing trends in Diabetes mellitus patients with other co-morbid conditions.
\end{abstract}

Methods: A prospective observational study was conducted on inpatients admitted to various wards in a tertiary care hospital for period of 6 months between October 2016- March 2017. Prescriptions of the patients are collected in a designed questionnaire form and the relevant information is recorded and analysed.

Results: 235 patient prescription patterns were studied, out of which $62.97 \%$ were males and $37.02 \%$ were females. Most of the patients were in the age group of $41-60$. Hypertension was the most commonly found co-morbid condition. Rapid acting insulin was mostly prescribed during hospital stay. Metformin was the commonly prescribed oral hypoglycemic agent followed by glimeperide.

Conclusion: The adverse drug reactions can be minimized by replacing the drugs with novel therapeutic agents like Glucagon-like peptide agonist, Dipeptidyl peptidase inhibitors and Sodium-glucose transport inhibitors. The management of drug interactions should be done by clinical significance and correlation.

Keywords: Diabetes mellitus - Spine surgery - Complication - Informatics for Integrating Biology and the Bedside (i2b2) - Outcome study - Electric medical record

Submitted: 20 September 2017; Accepted: 09 November 2017; Published online: 17 November 2017

\section{Introduction}

\section{Prescription pattern analysis}

Prescription pattern analysis is defined as insight regarding the existing drug usage to ensure rational drug therapy [1]. Prescription is one of the most important tools that communicate between the physician and the patient and also a written order of medication schedule to the patient [2].

\section{Diabetes mellitus: An alarmingly growing disorder}

Diabetes Mellitus (DM) is a group of metabolic disorders characterized by hyperglycemia. It is associated with abnormalities in carbohydrates and fat metabolism, which results in chronic complications including microvascular and macrovascular disorders [3].

The major challenge in patients with diabetes is to prevent from complications and improving the quality of life. Diabetes mellitus accounts for a significant proportion of morbidity and mortality in all age groups and therefore emerging as an important public health concern [4].
Mohd Mahmood*, Ronda Charitha Reddy, J R Soumya Lahari, Sadiya Fatima,

Pooja Shinde, S Anand Reddy, Pranali S Pandit

Department of Pharmcy, Malla Reddy Pharmacy College, Hyderabad, Telangana

*Author for correspondence:

E-mail: drmahmoodpharmd@gmail.com 


\section{Types of Diabetes Mellitus}

Resistance to the action of insulin, insufficient insulin secretion or both is the characteristic feature of Diabetes mellitus, which further classified into Type I, Type II, and Gestational diabetes [5].

Type $1 \mathrm{DM}$ is formerly referred to as insulin dependent diabetes mellitus (IDDM), which is caused by an absolute deficiency of insulin and results from autoimmune destruction of $\beta$ cells.

Type $2 \mathrm{DM}$ is formerly known as non-insulin dependent diabetes mellitus (NIDDM), which is caused by the presence of insulin resistance with an inadequate compensatory increase in insulin secretion with progressively lower insulin secretion over time.

Gestational diabetes mellitus (GDM) is defined as glucose intolerance that is first recognized during pregnancy. GDM complicates approximately $7 \%$ of all pregnancies.

\section{Pathophysiology}

Type $1 \mathrm{DM}$ accounts for 5 to $10 \%$ of all diabetes cases. It generally develops in childhood or early adulthood and results from immune mediated

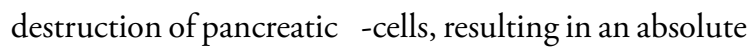
deficiency of insulin. There is a long preclinical period (up to 9 to 13 years) marked by the presence of immune

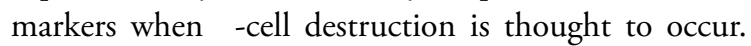
Hyperglycemia occurs when 80 to $90 \%$ of $\bigotimes$ - cells are destroyed. There is a transient remission ("honeymoon" phase) followed by established disease with associated risks for complications and death. The factors that initiate the autoimmune process are unknown, but the process is mediated by macrophages and $\mathrm{T}$ lymphocytes

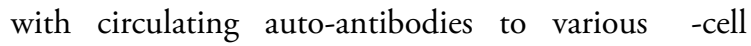
antigens (e.g., islet cell antibody, insulin antibodies). Type $2 \mathrm{DM}$ accounts for as many as $90 \%$ of DM cases and is usually characterized by the presence of both insulin resistance and relative insulin deficiency. Insulin resistance is manifested by increased lipolysis and free fatty acid production, hepatic glucose production, and decreased skeletal muscle uptake of glucose. Q-Cell dysfunction is progressive and contributes to worsening blood glucose control over time. Type $2 \mathrm{DM}$ occurs when a diabetogenic lifestyle (excessive calories, inadequate exercise, and obesity) is superimposed upon a susceptible genotype [3]

\section{Management}

The primary goal of the management of diabetes mellitus (DM) is to prevent the micro vascular complications, reduce mortality and improve the quality of life.

\section{Insulin}

Insulin which is mainly used in treatment for type 1 DM can also be used in type $2 \mathrm{DM}$ in patients whose pancreas produce less or no insulin or whose oral hypoglycemic agents do not control their blood glucose levels. Studies also showed that the obesity is the most common problem in type 2 diabetic patients, which contributes to insulin resistance [6]. Daily exercise for weight reduction and diet may help in improve the tissue sensitivity to insulin.

\section{Oral Hypoglycemic Agents (OHAs)}

\begin{tabular}{|c|c|c|}
\hline Class of drugs & Benefits & Risk factors \\
\hline $\begin{array}{c}\text { Insulin's } \\
\text { Short acting: } \\
\text { humulin R, } \\
\text { Novolin R } \\
\text { Intermediate } \\
\text { acting: NPH } \\
\text { Insulin } \\
\text { Long acting } \\
\text { insulin: Insulin } \\
\text { glargine. }\end{array}$ & $\begin{array}{l}\text { It treats the high } \\
\text { potassium levels. }\end{array}$ & $\begin{array}{l}\text { If proper diet } \\
\text { is not taken } \\
\text { it may lead to } \\
\text { hypoglycemia } \\
\text { and may lead } \\
\text { death. }\end{array}$ \\
\hline $\begin{array}{l}\text { Biguanides } \\
\text { e.g. Metformin }\end{array}$ & $\begin{array}{l}\text { First line } \\
\text { treatment, } \\
\text { used to treat } \\
\text { macro vascular } \\
\text { complications } \\
\text { and death. }\end{array}$ & $\begin{array}{c}\text { Lactic } \\
\text { acidosis, gastro } \\
\text { intestinal side- } \\
\text { effects }\end{array}$ \\
\hline $\begin{array}{l}\text { Sulphonylureas } \\
\text { e.g.chlopropamide }\end{array}$ & $\begin{array}{l}\text { It's used } \\
\text { to reduce } \\
\text { glycosylated } \\
\text { hemoglobin } \\
\text { (HbA1c) }\end{array}$ & $\begin{array}{l}\text { hypoglycemia, } \\
\text { weight } \\
\text { gain, liver } \\
\text { dysfunction } \\
\text { and } \\
\text { gastrointestinal } \\
\text { disturbance }\end{array}$ \\
\hline $\begin{array}{l}\text { Thiazolidinedi- } \\
\text { ones e.g. Piogli- } \\
\text { tazone }\end{array}$ & $\begin{array}{c}\text { Used in } \\
\text { combination } \\
\text { with } \\
\text { Metformin and } \\
\text { Sulphonylureas. } \\
\text { It reduce the } \\
\text { development } \\
\text { of diabetes in } \\
\text { patients with } \\
\text { impaired fasting } \\
\text { glycaemia }\end{array}$ & $\begin{array}{l}\text { Patients with } \\
\text { history of } \\
\text { heart failure, } \\
\text { symptoms } \\
\text { of coronary } \\
\text { ischemia } \\
\text { may lead to } \\
\text { complications. }\end{array}$ \\
\hline
\end{tabular}




\begin{tabular}{|c|c|c|}
\hline $\begin{array}{c}\text { Alpha-glycosidase } \\
\text { inhibitors } \\
\text { e.g. Acarbose }\end{array}$ & $\begin{array}{c}\text { Used in patients } \\
\text { who cannot } \\
\text { use other oral } \\
\text { hypoglycemic } \\
\text { drugs }\end{array}$ & $\begin{array}{c}\text { Improper use } \\
\text { may lead to } \\
\text { flatulence, } \\
\text { diarrhea. }\end{array}$ \\
\hline & $\begin{array}{c}\text { It's used as third } \\
\text { line therapy in } \\
\text { combination } \\
\text { Meglitinides } \\
\text { e.g. Exenatide } \\
\text { or glitazone }\end{array}$ & $\begin{array}{c}\text { Hypersensitivi- } \\
\text { ty reactions } \\
\text { occurs such as } \\
\text { anaphylaxis, } \\
\text { angioedema }\end{array}$ \\
\hline
\end{tabular}

\section{Background}

A study reported that the incidence of type $2 \mathrm{DM}$ has been highly increased from 3.6 a per 1000 persons year in 2000 to 3.99 per 1500 persons year. The incidence of diabetes mellitus was majorly seen in older males who are socially deprived. Metformin usage was increased from to $83.6 \%$ and Sulphonylureas usage was decreased to $41.7 \%$. However, they both remained first line agents. Thiazolidinediones (TZDs) and incretin based therapies are rarely used as first line agents in management of diabetes mellitus [7].

In a recent study has found that with the emergence of novel therapeutic agents in the management of diabetes mellitus; the prescribing trend is among towards the combination therapy, particularly dual therapy i.e.; OHA and insulin therapy. Metformin is gradually replacing the sulfonylurea as the first line agent in treatment of diabetes mellitus. They have identified that sulfonylurea usage has been declined from $51.5 \%$ in 2003 to $41.7 \%$ in 2006 [8].

There have been significant shifts occurred in usage of medication in diabetes therapy. Then in 1994 the pharmacotherapy was divided between insulin preparations and Sulphonylureas. Later in 2007, the Biguanides, incretins, glitazone, dipeptidyl peptidase -4 inhibitors have been the most frequent therapies. Nearly all insulin's were in the form of regular and intermediate acting. But later in 2001, the use of rapid acting insulin was increased in combination with older insulin. The intermediate acting insulin usage was decreased from $4.8 \%$ to $2.2 \%$ [9].

It has been showed that monotherapy with metformin and glibenclamide is more effective. The doses were not individualizing according to the age or other factors but the dose of Sulphonylureas have been decreased to reduce adverse effects or based on patient's response to the therapy. They also noticed that introduction of insulin therapy in type2 DM improves the glycemic control to decrease the HbA1c levels for patients over
9\%. The doses for monotherapy were lower than used in polytherapy [10].

Study conducted on GLP-1 receptor agonists have all been extensively evaluated in phase III clinical programs. Through a review of phase III clinical programs for Exenatide twice daily, Exenatide once weekly, liraglutide, albiglutide, lixisenatide, and dulaglutide, and identified that primary efficacy endpoint in all of the trials was changed in $\mathrm{HbA1C}$ from baseline with a no inferiority margin of $0.4 \%$ [11].

GLP-1 receptor agonists are effective agents for the treatment of type 2 diabetes, which have many advantages over other agents, such as weight loss, betacell protection, and low risks of hypoglycemia. Apart from that, there are positive benefits on cardiovascular parameters, including reductions in blood pressure, lipids, and weight, although the clinical relevance of this remains to be determined. Additionally, because GLP1 receptor agonists are available in a variety of forms, including twice-daily injections, once-daily injections, and once-weekly injections, patient satisfaction with these agents may be improved - as the patient is able to utilize the agent that best fits for the patient's lifestyle. Although long-term safety data is unavailable due to the short duration of time that these agents have been on the market, future studies will provide guidance to practitioners on the appropriate choice of agent to mitigate risk, including cardiovascular risk. Overall, GLP-1 receptor agonists are effective and innovative agents for patients with type 2 diabetes and other chronic conditions, who are either uncontrolled or intolerant to first-line metformin therapy [12].

SGLT1 inhibition improves glucose homeostasis by reducing dietary glucose absorption in the intestine and by increasing the release of gastrointestinal incretins like glucagon-like peptide-1. SGLT1 inhibition has a small glucosuric effect in the normal kidney and this is increased in diabetes and during inhibition of SGLT2, which deliver more glucose to SGLT1 in late proximal tubule. In short-term studies, inhibition of SGLT1 and combined SGLT1/SGLT2 inhibition appeared safe. However, more data is needed on long-term safety and cardiovascular consequences of SGLT1 inhibition [13].

\section{Aim and Objectives}

\section{AIM}

To analyze the prescription pattern of anti-diabetic drugs, insulin treatment and its combination therapy in patients with Diabetes mellitus with or without comorbidities admitted to various wards in a tertiary care hospital. 


\section{OBJECTIVES}

- To analyse the demographic information of the enrolled patients.

- To analyse the patterns of use of major pharmaceutical drug classes given for diabetes and comorbidities.

- To know the current use of anti-diabetics and their rational use.

- To identify and analyse the prescriptions with polypharmacy.

Apart from the treatment with medicines diabetes also requires life style modifications which rely upon diet and regular exercise [14].

\section{Need for the study}

Prescription analysis helps to improve the rational use of drugs. It helps in knowing the errors and improper prescribing, major problem identified in hospitals these days. It also helps us to provide advantageous feedback to prescribers in order to improve their prescribing behavior. We planned to carry out the study in diabetic patients with focus on outlook of "How the antidiabetic drugs are being prescribed" which helps in understanding various factors such as over and under consumption of drugs, greater use of newer expensive medicines particularly Human analogue insulin. With increase in prevalence of Diabetes, there may be increase in associated complications and co-morbidities which leads to increase in the number of drugs in the prescription which in turn leads to irrational drug use as a result of polypharmacy.

\section{Materials and Methods}

\section{Study design}

A prospective observational study is conducted in the inpatients admitted to various wards in the hospital.

\section{Study population}

The study group consists of 235 patients, both male and female diagnosed with Diabetes and diabetes with other co-morbid conditions, admitted in a tertiary care hospital.

\section{Study duration}

The study was carried out for 6 months from 2016 October to March 2017.

\section{Study site}

Mediciti Institute of Medical Sciences and College, Ghanpur village, Medchal district.

\section{Source of data}

All the relevant and necessary data for the study was collected from the patient profile forms, patient medication charts, and interviewing patients and health care professionals in a form that is suitable for the study.

\section{Study procedure}

The study teams visits the study site on regular basis and selects the patients according to the study criteria, then take the verbal consent from patient, the necessary data is collected from the patient and their patient profile forms and medication chart in a designed data collection form.

\section{Selection of subjects}

The patients or the subjects were selected or taken into this study according to the following inclusion and exclusion criteria

\section{Inclusion criteria}

- Patients of both sexes irrespective of age.

- Patients diagnosed with Diabetes Mellitus.

- Patients with Diabetes along with other comorbidities were selected.

- Patients with DM on treatment with oral hypoglycemic agents and insulin therapy.

- Laboratory investigations.

\section{Exclusion Criteria:}

- Patients without Diabetes mellitus and other ambulatory conditions such as poisoning and accident cases were excluded from study.

- Pediatric patients were also excluded from study.

- Patients with Gestational Diabetes are also excluded from study.

- Patients visiting out-patient departments with or without Diabetes Mellitus are also excluded from the study.

\section{RESULTS}

To assess prescription pattern of the Diabetic patients with or without co-morbidities, the data has been collected from 235 patients admitted to Mediciti hospital. And the observations are as follows:

\section{Categorization of diabetes mellitus}

Among 235 patients in the study population, Type $2 \mathrm{DM}$ is the common type of Diabetes mellitus, it accounts for $97 \%$ of patients, whereas Type 1 was not 
commonly found and accounts for only $3 \%$ of total cases collected (Table 1).

\section{Demographical data:}

Gender wise distribution: Among 235 patients enrolled in study, majority of the population included Male patients, $148(62.97 \%)$ followed by females patients, 87 (37.02\%) (Table 2).

Age wise distribution: Among 235 patients of study population with age group ranging between 20 to 90 years, majority were of age group 41 to 60 years $(45.53 \%)$ and the least were in the age group of 20 to $40(6.38 \%)$ (Table 3).

Physical activity: According to the study, among 235 patients $188(80 \%)$ of patients had No form of physical activity, 27(11.48\%) patients were undergoing physiotherapy, $20(8.51 \%)$ were doing regular exercise (Table 4).

Family history: As we know genetic factors play an important role in causing DM, Among 235 patients $81(34.46 \%)$ patients have a family history of DM, 123 $(52.34 \%)$ patients did not have a family history of DM and $31(13.19 \%)$ patients were not aware of their family history (Table 5).

\section{Investigations}

BMI range: We have analyzed the BMI values of the patients in our study and noticed that, the majority of the patients (i.e. 39.57\%) are at minor risk (Table 6).

Range of HbA1c levels in patients: $\mathrm{HbA1c}$ provides a longer term trend, similar to an average of how high blood sugar levels have been over a period of time,

\begin{tabular}{|lcc|}
\hline Table 1.Categorization of Diabetes mellitus & \\
\hline TYPE OF DM & NUMBER OF PATINTS & PERCENTAGE (\%) \\
\hline Type 1 & 7 & 2.97 \\
\hline Type 2 & 228 & 97.02 \\
\hline
\end{tabular}

\begin{tabular}{|lcc|}
\hline \multicolumn{3}{|l|}{ Table 2.Gender wise distribution of Diabetes patients: } \\
\begin{tabular}{|lcc|}
\hline GENDER & NUMBER OF PATIENTS & PERCENTAGE (\%) \\
\hline Male & 148 & 62.97 \\
\hline Female & 87 & 37.02 \\
\hline
\end{tabular}
\end{tabular}

\section{Table 3.Age wise distribution of Diabetic patients}

\begin{tabular}{|lll|}
\hline AGE (in years) & NUMBER OF PATIENTS & PERCENTAGE (\%) \\
\hline $20-40$ & 15 & 6.38 \\
\hline $41-60$ & 107 & 45.53 \\
\hline $61-70$ & 77 & 32.76 \\
\hline $71-90$ & 36 & 15.31 \\
\hline
\end{tabular}

In the study majority of the population had HbA1c ranging between $6.5-8.5$ that is $52.7 \%$ (Table 7).

Blood glucose levels: During the study period, regular monitoring of the blood glucose levels was done, $72.3 \%$ of the patients had controlled blood glucose levels after the therapy. And $1.27 \%$ patients were hypoglycemic, in $24.6 \%$ of patients the glucose levels were Not controlled, in $1.70 \%$ there was uncontrolled DM (Table 8 ).

\section{Prescribing pattern of anti-diabetic drugs}

Oral hypoglycemic therapy: The oral hypoglycemic drugs are most commonly used in the studied patients as most of them are affected with type2 diabetic mellitus. The standard dose of metformin is given to $57.3 \%$ of the patients over all. Whereas combination of Glimepiride+Metformin is given to $17.64 \%$ of the patients in order to overcome insulin resistance (Table 9).

Insulin and combinations per prescription: Based on the observation study carried out to analyze the pattern of drugs in diabetic mellitus, we have noticed that $56.1 \%$ were being given rapid acting insulin to control their blood glucose levels and $21.2 \%$ of the patients are being treated with the insulin (Table 10).

\begin{tabular}{|c|c|c|}
\hline EXERCISE & NUMBER OF PATIENTS & PERCENTAGE (\%) \\
\hline Yes & 20 & 8.51 \\
\hline No & 188 & 80 \\
\hline Physiotherapy & 27 & 11.48 \\
\hline
\end{tabular}

\begin{tabular}{|c|c|c|}
\hline $\begin{array}{l}\text { FAMILY HISTORY } \\
\text { OF DM }\end{array}$ & $\begin{array}{l}\text { NUMBER OF } \\
\text { PATIENTS }\end{array}$ & $\begin{array}{c}\text { PERCENTAGE } \\
(\%)\end{array}$ \\
\hline Yes & 81 & 34.36 \\
\hline No & 123 & 52.34 \\
\hline Not significant & 31 & 13.19 \\
\hline
\end{tabular}

\begin{tabular}{|c|c|c|}
\hline BMI RANGE & NO.OF PATIENTS & PERCENTAGE (\%) \\
\hline Minor (17-24) & 93 & 39.57 \\
\hline Moderate (25-27) & 72 & 30.63 \\
\hline High (28-40) & 66 & 28.05 \\
\hline Severe $(40-50)$ & 4 & 1.70 \\
\hline
\end{tabular}

Table 7.HbA1clevels in diabetic patients:
\begin{tabular}{|l|c|c|}
\hline HbA1c LEVELS & NUMBER OF PATIENTS & PERCENTAGE (\%) \\
\hline$<6.5$ & 69 & 29.3 \\
\hline $6.5-8.5$ & 124 & 52.7 \\
\hline $8.5-10.5$ & 31 & 13.1 \\
\hline$>10.5$ & 14 & 5.95 \\
\hline
\end{tabular}




\begin{tabular}{|lcc|}
\hline Table 8. Range of Blood Glucose Levels: & \\
\hline $\begin{array}{l}\text { BLOOD GLUCOSE } \\
\text { LEVELS }\end{array}$ & $\begin{array}{c}\text { NUMBEROF } \\
\text { PATIENTS }\end{array}$ & $\begin{array}{c}\text { PERCENTAGE } \\
\text { (\%) }\end{array}$ \\
\hline Controlled & 170 & 72.3 \\
\hline Not controlled & 58 & 24.6 \\
\hline Uncontrolled & 4 & 1.70 \\
\hline Hypoglycemia & 3 & 1.27 \\
\hline
\end{tabular}

Table 9. Oral hypoglycemic drug pattern used during study

$\left.\begin{array}{|lcc|}\hline \text { NAME OF DRUG } & \begin{array}{c}\text { NUMBER } \\ \text { OF } \\ \text { PATIENTS }\end{array} & \begin{array}{c}\text { PERCENTAGE } \\ \text { (\%) }\end{array} \\ \text { Metformin } & 78 & 57.3 \\ \text { Glimeperide } & 13 & 9.55 \\ \text { Glimeperide+Metformin } & 24 & 17.64 \\ \text { Sitagliptin+Metformin+ } & 10 & 7.35 \\ \text { Glimeperide } & 4 & 2.94 \\ \text { Voglibose } & 3 & 2.2 \\ \text { Pioglitazone+metformin+vogli- } \\ \text { bose }\end{array}\right)$

\begin{tabular}{|c|c|c|}
\hline TYPE OF INSULIN & $\begin{array}{c}\text { NO.OF } \\
\text { PATIENTS }\end{array}$ & $\begin{array}{c}\text { PERCENTAGE } \\
\text { (\%) }\end{array}$ \\
\hline Rapid acting insulin & 132 & 56.1 \\
\hline Intermediate acting insulin & 27 & 11.4 \\
\hline Rapid acting+long acting insulin & 13 & 5.5 \\
\hline Rapid acting+intermediate acting & 13 & 5.5 \\
\hline No insulin & 50 & 21.2 \\
\hline
\end{tabular}

\section{Discussion}

A total of 235 diabetic patients with or without comorbidities admitted in different wards of Mediciti hospital were enrolled in the study from October 2016 to March 2017.

According to the result obtained male patients are more than that of the female, male patients account for $62.97 \%$ of the total data collected. This may be due to their social habits and lifestyle changes. There are more than $24 \%$ patients who are both alcoholic and smoker in the study population, smoking disturbs the blood flow and metabolic action in the body and may lead to serious diabetic complications. Poor blood flow in the legs and feet that can lead to infections, ulcers, and possible amputation (removal of a body part by surgery, such as toes or feet), retinopathy (an eye disease that can cause blindness), peripheral neuropathy (damaged nerves to the arms and legs that causes numbness, pain, weakness, and poor coordination) and people with diabetes who smoke are more likely than nonsmokers to have trouble with insulin dosing and with controlling their disease. Whereas tobacco use increases the blood sugar levels and lead to insulin resistance.

The use of alcohol effects diabetic patients, if alcohol intake increases it may lead to chronic inflammation disorder of pancreas which can impair its ability to secret insulin.

According to the study diabetes prevalence is high in the age group of 41-60. This implies that these subjects develop DM in the most productive years of their life, because of their lifestyle modification, increase in stress rates and various physical changes in the body. So this age group also has a great chance of developing various other chronic complications associated with diabetes. The burden of diabetes is mainly due to consequence of long term complications like macrovascular and microvascular complications of disease.

Prevalence of hypertension is high in diabetes patients. It may be because of metabolic action of insulin, which indirectly affects the metabolism of the body. Hypertension and diabetes are interrelated disorders and independent causative factors associated with cardiovascular disease, cerebrovascular accidents, peripheral vascular disease and renal disorders and prevalence of various microvascular complications is high in diabetes patients such as diabetic foot which was seen in $15 \%$ of total diabetic patients collected during the time period of the study.

Report of this observational study shows that, tight control of blood sugar level in diabetes to near normal can minimize the various microvascular and macrovascular complications. In the present study majority of the patients have HbA1c levels between 6.5-8.5 and regular monitoring of the blood sugar levels helped in controlling the blood sugar level for $72.3 \%$ of the diabetes patients. Majority of the patients are at minor risk according to the BMI range.

Pharmacotherapy for both the types of diabetes mellitus has dramatically changed in last few years. Several new classes of drugs have been introduced. Symptomatically patients have been treated with various types of insulin and oral hypoglycemic therapy, depending on their requirements. Patients with HbA1c equal to $7 \%$ or less are usually treated with lifestyle measures and an agent which will not cause hypoglycemia. Those with HbA1c> 7\% but $<8.5 \%$ could be initially treated with single oral agents, or low dose combinations. Patients with higher initial 
HbA1c may benefit from initial therapy with two oral agents or even insulin. The best oral therapy for obese patients with type $2 \mathrm{DM}$ without contraindications is to start metformin. Lean patients can be treated with insulin secretagogues. If the therapeutic goal is not attained with initial therapy, additional oral agents can be added. Type 2 DM should be treated by matching therapy to the suspected underlying problem. Triple therapy is often with metformin, a sulfonylurea, and a TZD or DPP-4 inhibitor, but a good alternative is to use metformin, a TZD, and a GLP-1 agonist, which can lower glucose levels and increase satiety, reducing the weight gain potential of a TZD, and still has a low risk of hypoglycemia. If the HbA1c is $>8.5 \%$ to $9 \%$ on multiple therapies, insulin therapy should be considered.

In our study majority of the diabetic patients have been given monotherapy with either oral hypoglycemic drugs or insulin. Majority of the patients have received metformin as their oral therapy, and rapid acting insulin. Additionally, this drug does not cause weight gain and therefore can be prescribed in obese patients and has lesser chance of hypoglycemic episodes compared to SUs. In addition to this, metformin may reduce the incidence of diabetes-related complications. In the newly diagnosed obese patients SUs and insulin are more effective than their lifestyle modifications.

Due to various co-morbidities antihypertensive, cardiovascular and various antibiotic drugs have been prescribed. The most commonly used antihypertensive drugs are ARBs and diuretics combinations. It showed that monotherapy with antihypertensive drugs was more common compared to combination therapy. Telmisartan is the most commonly used antihypertensive drug in this observational study. As per many studies, ARBs are better in diabetic hypertensive patients to protect from microvascular and macro vascular complications.

Aspirin is mostly used drug for cardiovascular disorders as primary prevention anti-platelet therapy, and is recommended for cardiovascular complications in diabetes patients.

Cephalosporin classes of antibiotics are widely prescribed in this observational study due to its action over both gram negative and positive bacteria.

According to the report collected from this observational study majority of the patients are with co-morbidities and is on polypharmacy. Since there is an evidence of polypharmacy the patients should be educated and guided regarding their therapies and its positive and negative consequences. In order to prevent irrational use of drugs, frequent monitoring can help the patient for better outcome. Branded drugs were prescribed more than that of the generic drugs in study. Due to polypharmacy there is a chance of drug interactions and these drug interactions can be avoided by maintaining a time gap between the administration of drugs. There were adverse drug reactions with Insulin and metformin. These adverse drug reactions can be reduced with use of drugs which got less adverse drug reactions and more therapeutic efficacy like GLP-1 agonists and Sodium-glucose transport inhibitors, a novel class of agents in treatment of DM.

\section{Conclusion}

The present study was aimed to analyze the prescription pattern of the diabetic patients with or without comorbidity with specific objective to determine the current trend of anti-diabetic drugs.

The study was carried out in the Mediciti hospital from October 2016 to march 2017 and the data was collected from the 235 diabetic patients associated with other comorbidities.

According to the report obtained from the study, the male patients are more prone to diabetes mellitus than females. Type 2 diabetes mellitus is widely observed where study was carried out. There is the need for change in the lifestyle of diabetic patients as per observed social habits. The diabetes patients were in the age group of 41-60 years. Hypertension affected more than $50 \%$ of diabetic patients according to the present study. The prescription pattern of antihypertensive drugs and cardiovascular drugs are based upon the guidelines and single drug was used than combination drugs by majority of the diabetic patients.

The drugs pattern of oral hypoglycemic is also based upon the National list of essential medicines (NLEM 2015) and monotherapy with metformin is widely prescribed among this subjects. Proper dose calculations of insulin have been carried out based upon the BMI levels and various other diagnostic parameters of diabetic patients (such as HbA1clevels and blood glucose levels). The blood glucose levels were properly maintained after the treatment of the disease.

The polypharmacy was high in the above study; it's due to various co-morbidities in the diabetic patients. In order to avoid irrational use of drugs and decrease the polypharmacy, certain IV fluids and drugs which are not that essential according to patient condition (as multivitamins, analgesics $\&$ antibiotics) can be avoided 
in prescription. As there is the high rate of polypharmacy it may also increase the cost of the prescription. The cost of the prescription can also be minimized by using generic compared to brand names. The adverse drug reactions can be minimized by replacing the drugs with novel therapeutic agents like Glucagon-like peptide agonist, Dipeptidyl peptidase inhibitors and sodiumglucose transport inhibitors. The management of drug interactions should be done by the clinical significance and correlation.

\section{Limitations and Future Directions}

\section{Limitations}

The present study did not include all the diabetic patients visited to hospital during the study period because of logical issues. Such enrollment would have given much clear data without exclusion of any patients.

There is no data base or disease registry available.

Cost of illness would have been done as previous or incidence based study.

\section{Future directions}

Prescription pattern study can be continued for few more years so that the trend could be assessed clearly averaging out year to year variations.

Incidence or prevalence based population study for cost illness can be conducted.

Executive summary

Background: The treatment options for Diabetes mellitus and their prescribing has increased over years. This needs appropriate selection of drugs. The main objective of this study was to highlight the current prescribing trends in patients having Diabetes mellitus with other co-morbid conditions.

Methods: A prospective observational study was conducted in the inpatients admitted to various wards in a tertiary care hospital for period of 6 months between October2016- march 2017.Prescriptions of the patients are collected in a designed questionnaire form and the relevant information is recorded and analysed.

Results: Prescription patterns were totally studied in 235 patients, out of which $62.97 \%$ were males and $37.02 \%$ were females. Most of the patients were in the age group of 41-60.Hypertension was the most commonly found co-morbid condition. Rapid acting insulin was mostly prescribed during hospital stay. Metformin was the commonly prescribed Oral hypoglycemic agent followed by glimeperide.

Conclusion The adverse drug reactions can be minimized by replacing the drugs with novel therapeutic agents like Glucagon-like peptide agonist, Dipeptidyl peptidase inhibitors and sodium-glucose transport inhibitors. The management of drug interactions should be done by the clinical significance and correlation.

\section{References}

1. Bhanu P, Prasanand S, Divyashanthi CM, Annabelle R, Pandiamunian J. Prescribing pattern and WHO core prescribing indicators in post-operative patients of gynaecology department of tertiary care teaching hospital. Int J Basic Clin Pharmacol 6: 53-60 (2017).

2. Benet LZ. Goodman and Gilman's Principle of prescription order writing and patient compliance instructions: The Pharmacological basis of therapeutics 8: 1640-1649 (1991).

3. Dipiro JT, Talbert RL, Gary CY, Matzke GR, Wells BG, Michael P. Pharmacotherapy: A pathophysiologic approach 7: 1205-1241 (2008).

4. Wild S, Roglic G, Green A, Sicrre R, King H. Global prevalence of diabetes estimates for year 2000 and projections for 2030 . Diabetes Care 27: 1047-1053 (2004).

5. American Diabetes Association. Diagnosis and classification of Diabetes mellitus. Diabetes care 27: 5-10 (2004)

6. John D Piette, Wong, Edwin S, Liu, Chuan-Fen. Measures of adherence to oral hypoglycaemic agents at primary care clinic level: The role of risk adjustment. Medical care 50: 591-598 (2012).

7. Sharma M, Irwin N, Petersen I. Trends in incidence, prevalence and prescription in type 2 diabetes mellitus between 2000 and 2013 in primary care: A retrospective cohort study. BMJ 6: 1-9 (2016).
8. Hassan Y, Amuthaganesh M, Ahmed A. Trend in the use of oral hypoglycaemic agents in an out-patient pharmacy department of tertiary care hospital in Malaysia. Asian J Pharm Clin Res 2: 40-46 (2009).

9. Alexander GC, Niraj LS Rachael MM, Randall SS. National trends in treatment of type 2 diabetes mellitus. 1994 to 2007. Arch Intern Med 168: 2088-2094 (2008).

10. Guidonia CM, Anna Paula SB, Osvaldo.F, Leonardo Regi, Leira Pereira. Prescription pattern for diabetes mellitus and therapeutic implications: A population based analysis. Arq Bras Endocrinol Metab 56: 120-127 (2012).

11. Trujillo JM, Nuffer W, Ellis SL. GLP-1 receptor agonists: a review of head-to-head clinical studies. Ther Adv Endocrinol Metab 6: 19-28 (2015).

12. Reddy PL, Isaacs DA. Clinical review of GLP-1 receptor agonists: efficacy and safety in diabetes and beyond. Drugs Context 4: 212283 (2015).

13. Song P, Onishi A, Koepsell H, Vallon V. Sodium glucose cotransporter SGLT1 as a therapeutic target in diabetes mellitus. Expert Opin Ther Targets 20: 1109-1125 (2016).

14. Elis SL, Carter BL, Billups SJ. Maalone DC, Manson B, Jue $S$. Types of interventions made by clinical pharmacists in the IMPROVE study. Pharmacotherapy 20: 429-435 (2000). 